\title{
Excess hospital admissions for pneumonia and influenza in persons $\geqslant 65$ years associated with influenza epidemics in three English health districts: 1987-95
}

\author{
J. S. NGUYEN-VAN-TAM ${ }^{1 *}$, C. R. BROCKWAY ${ }^{2}$, J. C. G. PEARSON ${ }^{1}$, \\ A. C. HAYWARD ${ }^{1}$ AND D. M. FLEMING ${ }^{3}$ \\ ${ }^{1}$ Division of Public Health Medicine and Epidemiology, School of Community Health Sciences, \\ University of Nottingham Medical School, Queen's Medical Centre, Nottingham NG7 2UH, UK \\ ${ }^{2}$ Department of Public Health, Lincolnshire Health Authority, Lincoln, UK \\ ${ }^{3}$ Royal College of General Practitioners Research Unit, Birmingham, UK
}

(Accepted 10 September 2000)

\section{SUMMARY}

Objectives: To study the association between community influenza activity and acute hospital admissions for pneumonia and influenza among elderly persons.

Design: Multiple regression analysis of acute hospital admissions against community influenza activity, air temperature and seasonal and long-term trends.

Setting: Three English health districts: 1987-95.

Subjects: Persons aged $\geqslant 65$ years.

Outcome measures: Acute hospital admissions for pneumonia and influenza (ICD9: 480-487); excess hospital admissions during epidemic periods.

Results: The final regression model explained $70 \%$ of the total variation in hospital admissions for pneumonia and influenza, including $14 \%$ due to community influenza activity. However, most variation was explained by long-term and seasonal changes unrelated to influenza. In the large influenza epidemic of 1989/90 a typical health district (500000 total population) experienced 56 excess admissions for pneumonia and influenza attributable to epidemic influenza among persons aged $\geqslant 65$ years, requiring 672 additional bed-days. However the figure varied widely between seasons and over the whole study period, the average winter excess was 17.5 admissions per health district, requiring an additional 210 bed-days.

Conclusions: Influenza epidemics exert a variable impact on acute hospital admissions for pneumonia and influenza among elderly persons, which in the past have been poorly quantified. Although the absolute numbers of excess admissions is modest, their impact on bed availability may be considerable because of the duration of hospital stay in elderly persons.

\section{INTRODUCTION}

The association between influenza epidemics and excess mortality has been studied for over 150 years. In 1847 , Farr estimated excess mortality by counting the total number of deaths during an influenza epidemic and comparing this with the 'normal' figure for that time of year [1]. In 1930, Collins advanced this

\footnotetext{
* Author for correspondence.
}

technique by estimating expected mortality from moving averages calculated during non-epidemic periods [2]. In 1963, Serfling added greater mathematical sophistication by producing a smoothed sinusoidal curve of expected weekly mortality in the absence of influenza, as a 'baseline' [3]. In the 1970s this work was developed by Assad Cockburn and Sundaresan, who proposed a method of taking into account annual winter influenza activity regardless of 
its magnitude [4]. Finally, in 1977, Clifford and colleagues demonstrated a regression model which related mortality to indices of virological activity such as influenza laboratory isolates and general practitioner (GP) consultation rates for influenza and 'influenza-like illness', whilst simultaneously adjusting for other seasonal factors such as temperature [5]. This methodology allowed estimation of the mortality to be expected in the absence of influenza activity. Tillett and colleagues performed further age-specific analyses using the same technique in the early 1980s $[6,7]$.

The association between influenza epidemics and excess morbidity has also been well described [8-10] but no studies have applied the same mathematical rigour used for estimating excess deaths. In Britain, only excess sickness benefit claims related to influenza have ever been examined using regression analysis [6]. The major healthcare costs of influenza epidemics are recognized to occur in secondary care (hospital) settings owing largely to increases in the rate of acute respiratory admissions among elderly persons. In spite of this fact, excess hospital admissions attributable to influenza have not been widely studied or quantified $[9,10]$. We applied the method of calculating excess mortality utilized by Tillett, Smith and Gooch to the study of hospital admissions in three English health districts over a period of 8 years [7].

\section{MATERIALS AND METHODS}

\section{Data sources}

Data on acute hospital admissions for pneumonia and influenza in persons $\geqslant 65$ years were obtained from computerized records held at Lincolnshire, Nottingham and Southern Derbyshire health authorities for the period April 1987-March 1995 inclusive. Weekly counts of emergency (non-elective) admissions for pneumonia and influenza (ICD9: 480-487) were converted into age-specific rates (per $10^{5}$ population) using mid-year population estimates for each health district supplied by the Office for National Statistics.

The Royal College of General Practitioners (RCGP) Research Unit, Weekly Returns Service (WRS) provides data from a network of sentinel practices across England and Wales [11]. At the midpoint of this study (1991) the network included 94 practices and covered a total population of over 700000 persons. Weekly consultation rates for influenza and 'influenza-like illness' in persons $\geqslant 65$ years were obtained for the same 8-year period. These diagnoses are made predominantly on clinical grounds but in previous studies have been shown to be highly correlated over time with laboratory confirmed influenza infections detected by the Nottingham Public Health Laboratory, which are indicative of local influenza activity [12].

The UK Meteorological Office provided weekly averages for maximum and minimum air temperatures in Nottingham (the central district in the study). Data were also obtained on weekly maximum and average surface level ozone concentrations recorded at the UK Department of the Environment, Transport and the Regions (DETR) automatic monitoring station in Bottesford, Nottinghamshire (http://www.aeat.co. $\mathrm{uk} /$ netcen/airqual/). These data were not available for weeks 47-52 in 1987, and weeks 1-4 in 1995. Local data on other atmospheric respiratory pollutants, e.g. $\mathrm{NO}_{2}, \mathrm{SO}_{2}$ were not available for a sufficiently large enough proportion of the study period to justify their inclusion for modelling.

\section{Regression analysis}

Regression analysis was performed using SPSS for Windows v. 8.1.3, with hospital admission rate for pneumonia and influenza in persons over 65 years as the dependent variable.

The long-term trend in rate of hospital admissions was modelled by creating 15 dummy variables to represent the average changes over the 16 winter (weeks 40-13) and summer (weeks 14-39) periods studied. In addition, the overall winter seasonal pattern was modelled using five dummy variables to categorize weeks $40-44,45-48,49-52,1-4,5-8$, and 9-13.

The other variables used in modelling were maximum and minimum air temperature, maximum and average ozone concentration, and GP consultation rates for influenza among persons aged 65 years and over. Since excess deaths due to influenza and hospital admissions for pneumonia and influenza may lag behind GP consultation rates by $1-2$ weeks $[8,13]$, we also included the variables for GP consultation, air temperature and ozone concentration when lagged by 1 and 2 weeks.

Modelling was carried out in two stages. First, all of the variables representing long-term and seasonal trends were forced into the model. The other 
Table 1. Timing and duration of influenza epidemics in England and Wales, 1987/8-1994/5 (Royal College of General Practitioners Weekly Returns Service)

\begin{tabular}{|c|c|c|c|c|c|c|c|}
\hline \multirow{2}{*}{$\begin{array}{l}\text { Winter } \\
\text { season }\end{array}$} & \multicolumn{3}{|c|}{ Epidemic period (week number) } & \multirow{2}{*}{$\begin{array}{l}\text { Duration } \\
\text { (weeks) }\end{array}$} & \multirow{2}{*}{$\begin{array}{l}\text { Peak consultation } \\
\text { rate } / 10^{5} \text { population } \\
\text { (all ages) }\end{array}$} & \multirow{2}{*}{$\begin{array}{l}\text { Peak consultation } \\
\text { rate } / 10^{5} \text { population } \\
\text { (aged } \geqslant 65 \text { years) }\end{array}$} & \multirow{2}{*}{$\begin{array}{l}\text { Main } \\
\text { subtype }\end{array}$} \\
\hline & Start & Peak & Final & & & & \\
\hline $87 / 88$ & 4 & 12 & 14 & 11 & 128 & 70 & $\mathrm{H} 3 \mathrm{~N} 2 / \mathrm{H} 1 \mathrm{~N} 1$ \\
\hline $88 / 89$ & 48 & 51 & 4 & 9 & 190 & 112 & $\mathrm{H} 1 \mathrm{~N} 1 / \mathrm{H} 3 \mathrm{~N} 2$ \\
\hline $89 / 90$ & 46 & 49 & 3 & 10 & 583 & 526 & $\mathrm{H} 3 \mathrm{~N} 2$ \\
\hline 90/91 & 51 & 5 & 10 & 12 & 139 & 78 & B \\
\hline $91 / 92$ & 51 & 2 & 9 & 11 & 125 & 160 & $\mathrm{H} 3 \mathrm{~N} 2$ \\
\hline $92 / 93$ & 8 & 11 & 16 & 9 & 103 & 54 & B \\
\hline $93 / 94$ & 42 & 45 & 51 & 10 & 235 & 163 & $\mathrm{H} 3 \mathrm{~N} 2$ \\
\hline $94 / 95$ & 1 & 6 & 14 & 14 & 159 & 67 & B \\
\hline
\end{tabular}

Adapted with permission from Fleming and colleagues [14].

explanatory variables were then entered using the step-wise procedure, the model being checked at each stage for entering and removing variables. Once a model had been defined, its validity was checked, by examining the residuals for normality and constant variance. As a further check on the stability of the model, the second stage was repeated entering all of the non-trend variables and using the backwards regression procedure to eliminate those variables which did not contribute to the model.

Since the ozone data were missing during one of the influenza epidemics, the modelling was also carried out omitting the ozone variables, to avoid losing information on that epidemic.

\section{Calculation of epidemic threshold}

In order to be able to estimate the effect of influenza epidemics, it was necessary to define the expected nonepidemic level of consultation. This was done using the method described by Fleming and colleagues [14] where non-epidemic weeks were defined as those in which influenza virus detection by the Public Health Laboratory Service (PHLS) was very infrequent $(<1$ isolate/week). Average, baseline consultation rates for each week of the year were then obtained by calculating the mean level of the non-epidemic observations for that week, and finally smoothed by taking a 3-week moving average.

\section{Estimation of excess hospital admissions attributable to influenza}

The expected hospital admission rate in the absence of influenza epidemics was estimated by substituting the baseline, non-epidemic, consultation rates defined above for the observed consultation rates in the regression equation. The excess admissions attributable to each influenza epidemic were then estimated as the difference between the rates predicted using the observed and baseline consultation rates.

\section{RESULTS}

Table 1 shows the timing and duration of epidemic periods during each of the study seasons and the main influenza subtype in circulation. Figure 1 shows the variation in the rate of hospital admissions for pneumonia and influenza over the 8 years studied in relation to the occurrence and size of each epidemic. Figure 2 shows the weekly variation in both hospital admission rates for pneumonia and influenza and GP consultation rates for influenza. Increases in the rate of admissions were seen associated with some, but not all, epidemics.

The baseline pattern for GP consultation rates in the absence of epidemics is shown in Figure 3, where it is compared with the observed consultation rates and the timing of epidemic periods. The baseline shows the expected higher rates of consultation during the winter months, but these never exceed 50 consultations per $10^{5} /$ week. The baseline also shows a peak over the Christmas and New Year period, which appears unrelated to influenza activity.

The modelling process is shown in Table 2. The final model was able to explain more than $70 \%$ of the variation in the hospital admission rates, whether or not ozone was included. Following long-term trend and seasonal effects, which together explained more than $50 \%$ of the variation, GP consultations for the 


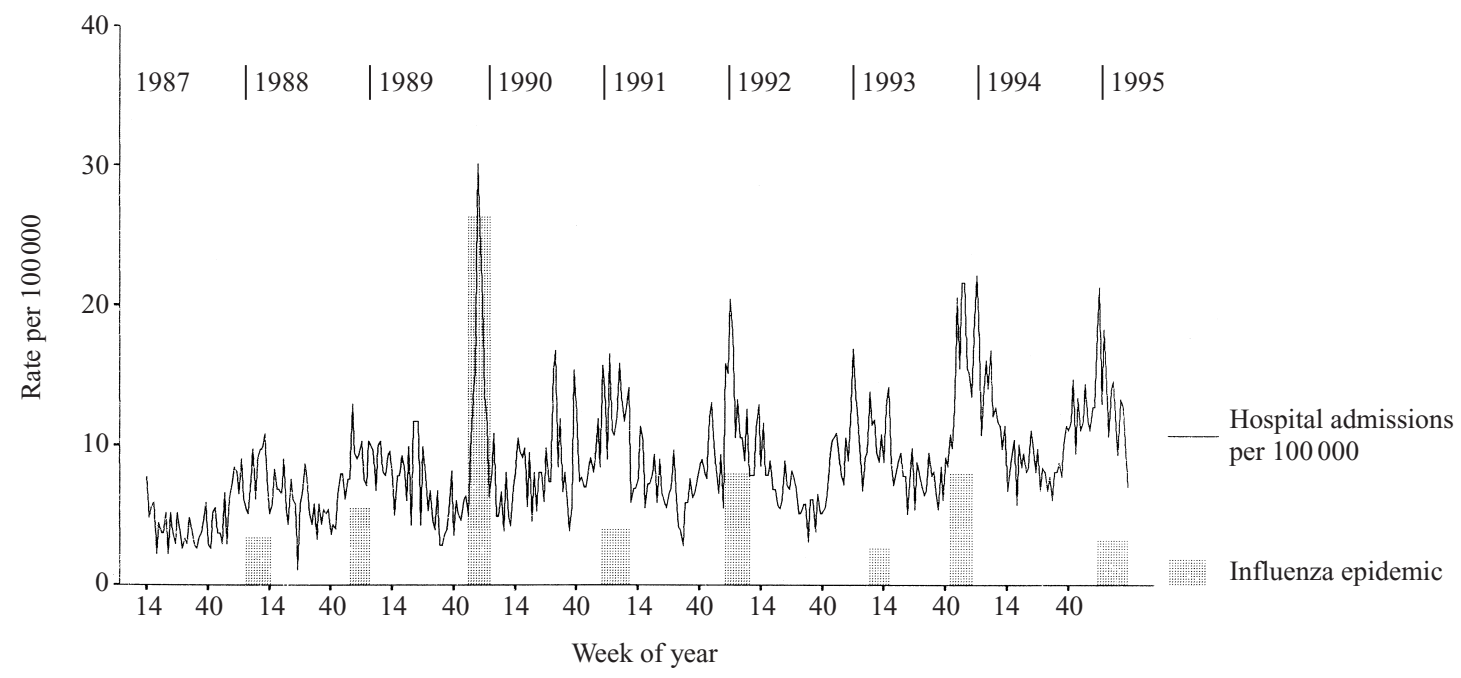

Fig. 1. Hospital admission rates per 100000 population for pneumonia and influenza in persons aged $\geqslant 65$ years during the period studied, in relation to the occurrence of influenza epidemics. Widths of columns show durations of epidemics; to indicate severity, heights are proportional to the maximum rate of consultations (age $\geqslant 65$ years) during the epidemic, the actual rates being shown in Table 1.

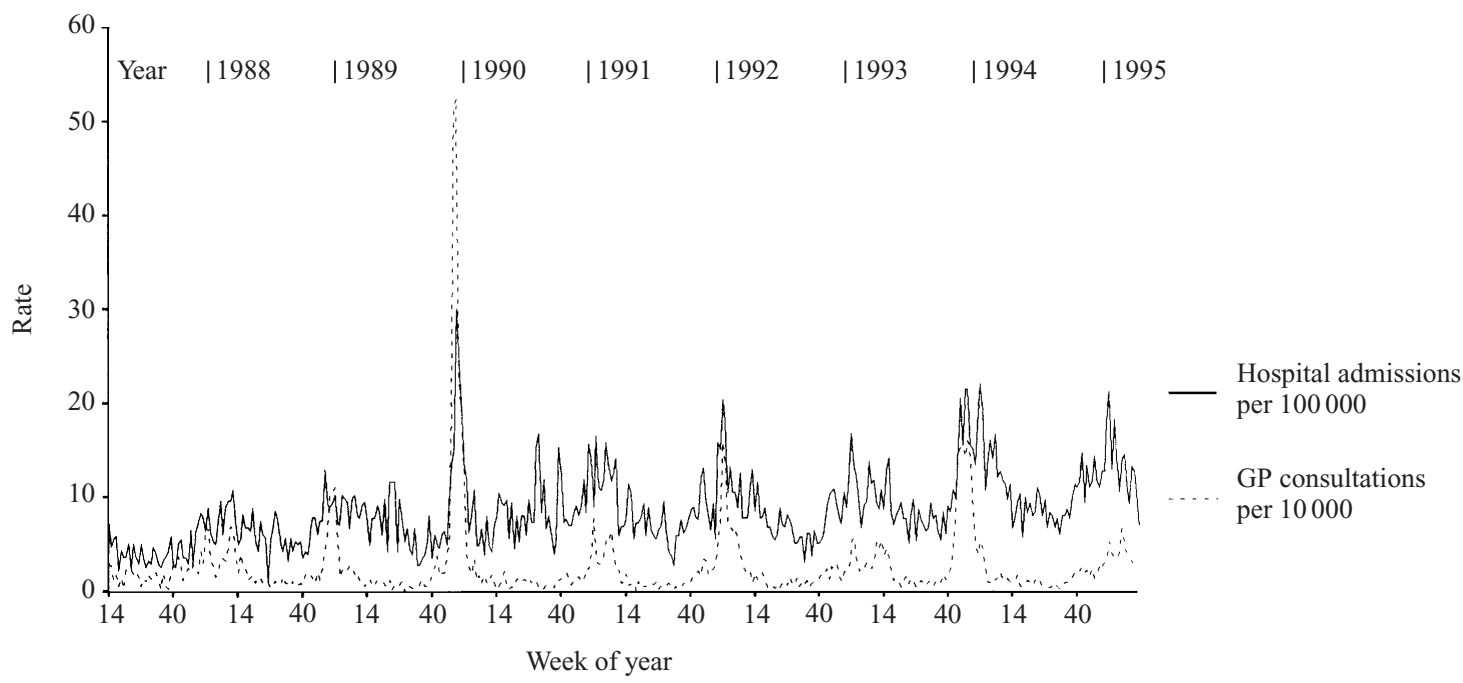

Fig. 2. Hospital admission rates per 100000 population for pneumonia and influenza and GP consultation rates per 10000 population, among persons aged $\geqslant 65$ years and over during the study period.

previous week was the next variable to enter each model, adding some $15 \%$ to the variation explained. Thereafter small contributions were made by other variables representing temperature and ozone (where used), and GP consultations for the current week also made a small but significant contribution. Similar models were obtained using the backwards procedure and in models restricted to the winter seasons. Minor changes occurred in relation to which of the temperature, ozone and consultation variables appeared in the final models. The different variables were all highly correlated and the selection of a particular variable was often based on very small differences. However, each final model contained GP consultation rate for the current and previous week, one main temperature variable, most frequently the maximum in the previous week and one main ozone variable, where these had been used. Other variables, which entered the models made very small contributions of less than $1 \%$ of the total variation, as shown in Table 2.

For the investigation of excess admissions attributable to influenza epidemics, a minimal model was chosen. In order to be able to examine all of the 


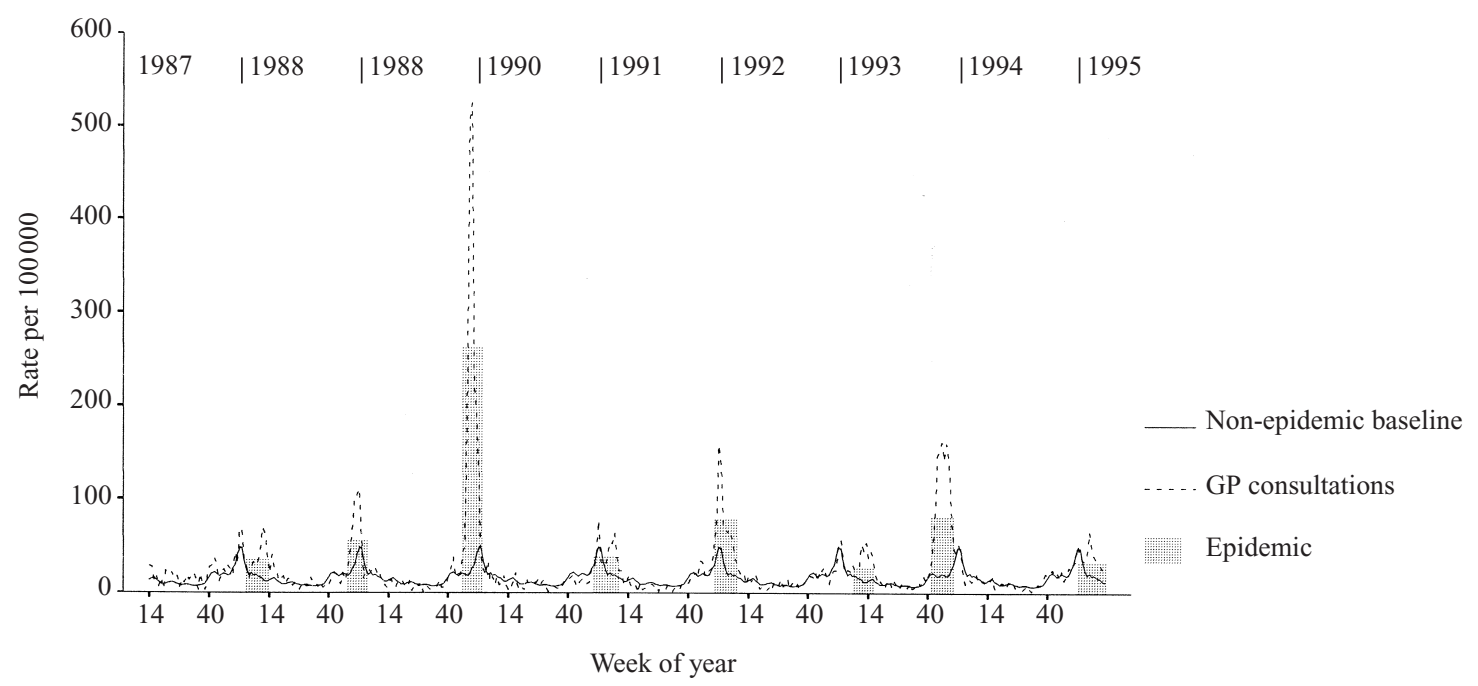

Fig. 3. Observed and baseline consultation rates for influenza in persons aged $\geqslant 65$ years in relation to influenza epidemics. Baseline rates calculated on 3-week moving average of mean consultation rates for non-epidemic weeks during the period of study. Widths of columns show durations of epidemics; to indicate severity, heights are proportional to the maximum rate of consultations (age $\geqslant 65$ years) during the epidemic, the actual rates being shown in Table 1.

Table 2. Derivation of model of rate of hospital admissions for influenza and pneumonia

\begin{tabular}{|c|c|c|c|c|}
\hline Model & Variable(s) entered & $\begin{array}{l}\text { Degrees of } \\
\text { freedom }\end{array}$ & $\begin{array}{l}\text { Change in } \\
\text { percentage } \\
\text { explained }\end{array}$ & $\begin{array}{l}\text { Percentage of } \\
\text { variation } \\
\text { explained by model }\end{array}$ \\
\hline \multicolumn{5}{|c|}{ (a) Including the ozone variables (no. of observations $=400$ ) } \\
\hline $1 *$ & Half-yearly trend & 15 & $41 \cdot 4$ & $41 \cdot 4$ \\
\hline $2 *$ & Winter seasonal effect & 5 & $10 \cdot 4$ & $51 \cdot 7$ \\
\hline $3 \dagger$ & GP consultations, lagged 1 week & 1 & $15 \cdot 3$ & $67 \cdot 1$ \\
\hline $4 \dagger$ & Maximum temperature, lagged 1 week & 1 & $2 \cdot 1$ & $69 \cdot 1$ \\
\hline $5 \dagger$ & Maximum ozone level, current & 1 & $1 \cdot 3$ & $70 \cdot 4$ \\
\hline $6 \dagger$ & GP consultations, current & 1 & $1 \cdot 1$ & $71 \cdot 5$ \\
\hline $7 \dagger$ & Maximum ozone level, lagged 2 weeks & 1 & $0 \cdot 5$ & $72 \cdot 0$ \\
\hline \multicolumn{5}{|c|}{ (b) Excluding the ozone variables (no. of observations $=414$ ) } \\
\hline $1 *$ & Half-yearly trend & 15 & $42 \cdot 6$ & $42 \cdot 6$ \\
\hline $2 *$ & Winter seasonal effect & 5 & $10 \cdot 4$ & $53 \cdot 0$ \\
\hline $3 \dagger$ & GP consultations, lagged 1 week & 1 & $14 \cdot 5$ & $67 \cdot 5$ \\
\hline $4 \dagger$ & Maximum temperature, lagged 1 week & 1 & $1 \cdot 8$ & $69 \cdot 4$ \\
\hline $5 \dagger$ & GP consultations, current & 1 & $1 \cdot 0$ & $70 \cdot 4$ \\
\hline $6 \dagger$ & Minimum temperature, lagged 2 weeks & 1 & $0 \cdot 3$ & $70 \cdot 7$ \\
\hline $7 \dagger$ & Maximum temperature, current & 1 & $0 \cdot 5$ & $71 \cdot 1$ \\
\hline
\end{tabular}

* Forced entry of set of dummy variables

$\dagger$ Stepwise regression on variables: GP consultation rate, maximum and minimum temperatures, and maximum and average ozone concentrations, each for current week, lagged by 1 week and lagged by 2 weeks.

epidemic periods a model excluding ozone was selected and any variables adding less than $1 \%$ were dropped. The minimal model was therefore fitted using GP consultations for the current and previous week and maximum temperature in the previous week. The results for this model are shown in Table 3 and the observed and predicted hospital admission rates are shown in Figure 4. It can be seen that the model is a good predictor of admission rates for pneumonia and influenza.

Based on the model shown in Table 3, and the baseline rates in Figure 3, the excess hospital admissions that could be attributed to the occurrence of epidemics of influenza (as measured by GP consultation rates) are shown graphically in Figure 5. The total excess for each epidemic, together with the 
Table 3. Final model used in assessing the effect of influenza epidemics on hospital admission rates for pneumonia and influenza (no. of observations $=415$ )

\begin{tabular}{|c|c|c|c|c|}
\hline Variable & $\begin{array}{l}\text { Regression } \\
\text { coefficient } \dagger\end{array}$ & $\begin{array}{l}95 \% \text { Confidence } \\
\text { interval }\end{array}$ & $P \dagger$ & $\begin{array}{l}\text { Percentage } \\
\text { of variation } \\
\text { explained }\end{array}$ \\
\hline GP consultations, lagged by 1 week & $0 \cdot 0263$ & 0.017 to 0.035 & $<0.0005$ & $14 \cdot 1 \dagger^{*}$ \\
\hline GP consultations, current & $0 \cdot 0162$ & 0.007 to 0.025 & $<0.0005$ & \\
\hline Maximum temperature, lagged by 1 week & $-0 \cdot 152$ & -0.217 to -0.087 & $<0.0005$ & $1.6 \dagger$ \\
\hline $\begin{array}{l}\text { All of above adjusted for } \\
\text { time and seasonal variables }\end{array}$ & & & & $17 \cdot 3$ \\
\hline Full model & & & & $70 \cdot 4$ \\
\hline
\end{tabular}

$\dagger$ Adjusted for the other variables shown in this table, plus the half-yearly trend and seasonal effect.

* Contribution of the two GP consultation variables is shown as a single figure to express the total contribution made by GP consultations.

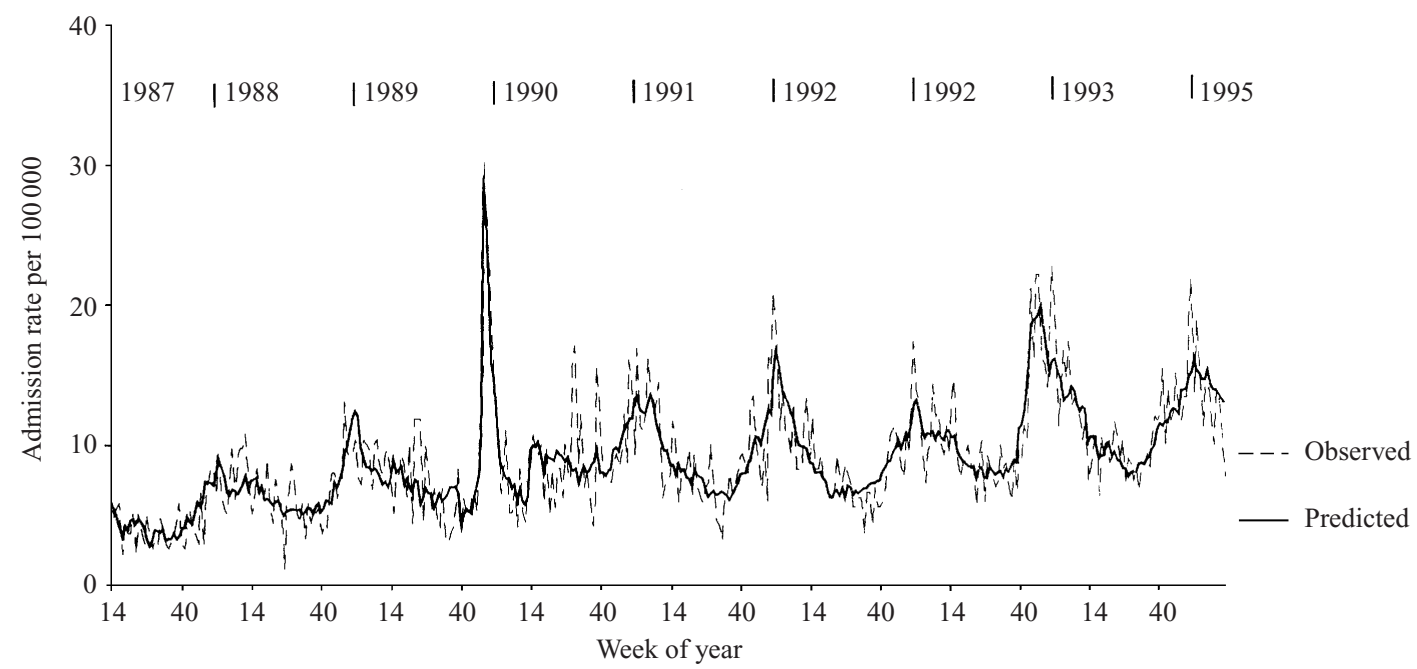

Fig. 4. Comparison of observed rate of hospital admissions for pneumonia and influenza in persons aged $\geqslant 65$ years, with predicted rate based on model shown in Table 3.

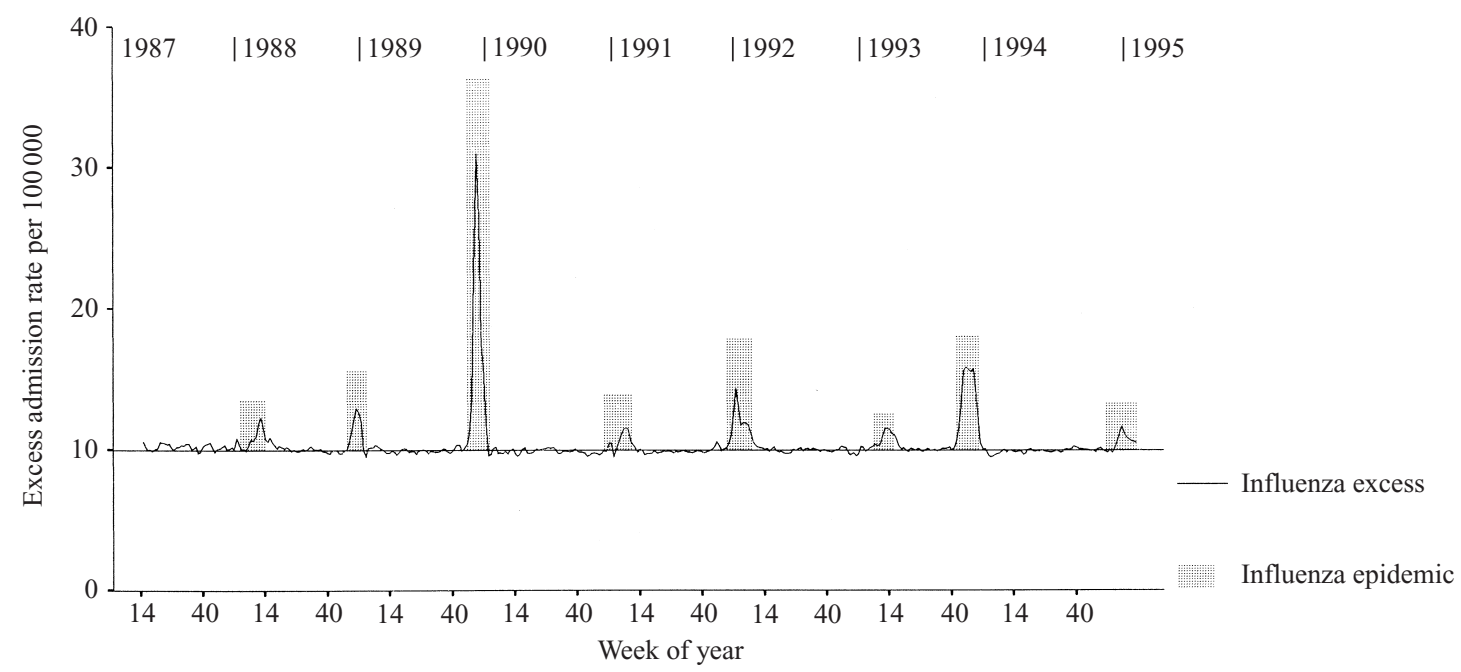

Fig. 5. Excess hospital admissions for pneumonia and influenza attributable to epidemics of influenza. Widths of columns show durations of epidemics; to indicate severity, heights are proportional to the maximum rate of consutations (age $\geqslant 65$ years) during the epidemic, the actual rates being shown in Table 1. 
Table 4. Excess hospital admissions for influenza and pneumonia attributable to influenza epidemics, 1987-95

\begin{tabular}{|c|c|c|c|c|c|c|}
\hline Epidemic & $\begin{array}{l}\text { No. of } \\
\text { weeks }\end{array}$ & $\begin{array}{l}\text { Peak } \\
\text { consultation } \\
\text { rate } / 10^{5} \\
\text { population } \\
\text { (aged } \geqslant 65)\end{array}$ & $\begin{array}{l}\text { Total excess } \\
\text { admissions } / 10^{5} \\
\text { population } \\
\geqslant 65 \text { years } \dagger\end{array}$ & $\begin{array}{l}\text { Maximum } \\
\text { weekly } \\
\text { excess } / 10^{5} \\
\text { population } \\
\geqslant 65 \text { years } \dagger\end{array}$ & $\begin{array}{l}\text { Impact on typical } \\
\text { health district } \dagger \\
\text { (number of } \\
\text { extra admissions } \\
\text { in persons } \\
\geqslant 65 \text { years) }\end{array}$ & $\begin{array}{l}\text { Impact on typical } \\
\text { health district* } \\
\text { (additional } \\
\text { bed-days in } \\
\text { persons } \\
\geqslant 65 \text { years) } !\end{array}$ \\
\hline Non-epidemic weeks & 330 & & 0.7 & .9 & 1 & 12 \\
\hline $1987 / 8$ & 11 & 70 & $9 \cdot 2$ & $2 \cdot 3$ & 7 & 84 \\
\hline 1988/9 & 9 & 112 & $11 \cdot 2$ & $3 \cdot 0$ & 9 & 108 \\
\hline 1989/90 & 10 & 526 & $69 \cdot 5$ & $21 \cdot 0$ & 56 & 672 \\
\hline 1990/1 & 12 & 78 & $7 \cdot 0$ & $1 \cdot 6$ & 6 & 72 \\
\hline $1991 / 2$ & 11 & 160 & $20 \cdot 8$ & $4 \cdot 7$ & 17 & 204 \\
\hline $1992 / 3$ & 9 & 54 & 8.9 & $1 \cdot 6$ & 7 & 84 \\
\hline $1993 / 4$ & 10 & 163 & $40 \cdot 8$ & 5.9 & 32 & 384 \\
\hline $1994 / 5$ & 13 & 67 & $7 \cdot 9$ & $1 \cdot 7$ & 6 & 72 \\
\hline All epidemics & 85 & & $175 \cdot 2$ & $21 \cdot 0$ & 140 & 1680 \\
\hline Total period & 415 & & $175 \cdot 8$ & $21 \cdot 0$ & 141 & 1692 \\
\hline
\end{tabular}

* England \& Wales: 1996-based national population projections.

$\dagger$ Total health district population $=500000$; elderly population $\geqslant 65$ years $=80000(16 \%)$.

$\$$ Based on median length of stay $=12$ days.

maximum weekly excess during the epidemic, is shown in Table 4. For each winter season, the data have been extrapolated to demonstrate the likely impact of excess acute admissions for pneumonia and influenza in a typical English health district of 500000 residents. During each of the three most recent winter seasons from 1996/7-1998/9 (data unavailable for earlier years) in the three health authority districts we studied, the median length of stay for pneumonia and influenza in persons aged $\geqslant 65$ years was 12 days. Therefore this figure was adopted to calculate bed-days used.

\section{DISCUSSION}

Most winters, especially around the Christmas/New Year holiday, the British NHS suffers an acute 'bed crisis'. When influenza activity occurs simultaneously, it is frequently blamed as the underlying cause. This hypothesis is supported by crude visual examination of the data on GP consultations for influenza and hospital admissions for pneumonia and influenza (Fig. 2). However, this study is the first in Britain to apply the principles used in estimating excess mortality due to influenza to the study of hospital admissions.

We chose to study persons aged $\geqslant 65$ years on the basis that most serious morbidity (hospitalization) occurs in this group [9, 10]. Our estimation of excess hospital admissions takes into account long-term trends in hospital admissions, seasonal effects, air temperature, surface level ozone and the baseline of hospital admissions to be expected in the absence of significant influenza activity.

The final model was a good predictor of excess hospital admissions due to pneumonia and influenza in elderly persons. However, long-term trend and seasonal variables explained the majority of the variation in hospital admissions. Of the other regressor variables, only GP consultation rates for influenza made a sizeable contribution to the model. Although this variable represents clinical diagnoses of influenza rather than virologically confirmed cases, it is well accepted as a good indicator of influenza incidence in the community [11]. This suggests that only $14 \%$ of the variability in hospital admissions for pneumonia can be attributed to epidemic influenza activity, which is perhaps less than expected. In comparison, the effects of temperature and surface level ozone were even smaller. Nevertheless, both findings are consistent with the known effects of these variables on respiratory disease $[15,16]$.

Since the model explained a total of $70 \%$ of the variability in hospital admissions for pneumonia in persons aged 65 years and over, it follows that if all possible contributory variables had been examined the remainder of the variation could be attributed to random chance. However we were unable to consider in the model the possible impact of respiratory syncytial virus (RSV) infections on hospitalization. 
Given that we showed a consistent peak in the nonepidemic baseline for GP consultations around each Christmas/New Year period (Fig. 1), that seasonal RSV activity peaks with remarkable consistency at that time of year and is recognized as an important cause of mortality in elderly persons [17], it may be that much of the unexplained variability in our model might be attributable to RSV.

Influenza is recognized to produce increased mortality over a wide range of diagnostic categories, notably deaths from cardiovascular disease $[7,18]$. In this study we considered its impact only on admissions for pneumonia and influenza (as opposed to all-causes acute medical admissions) and in elderly persons (as opposed to all ages). However, we also considered a model based on all acute medical admissions in elderly persons but found the fit to be much poorer (data not shown), suggesting that all-causes acute medical admissions are less strongly influenced by influenza activity. Similarly a model based on all-ages admissions for pneumonia and influenza also proved to be a poorer fit (data not shown), reflecting either the overriding importance of influenza in elderly persons, or the importance of RSV infection in children, or other factors associated with the time period surveyed.

On first inspection, the estimated numbers of excess admissions (Table 4) appear far smaller than expected. In addition, the impact of influenza on excess admissions was highly variable between seasons. For example, we estimated that in the severe epidemic of 1989/90, 56 excess admissions for pneumonia and influenza occurred among the 80000 elderly persons in a typical health district (total population 500000). However, over the study period, the average seasonal excess was 17.5 admissions. Two additional factors are important. Firstly, the main clinical impact of influenza is usually compressed into an epidemic period of 6-10 weeks so its effect on hospital bed usage is felt particularly acutely. Secondly the impact on hospital services is more meaningfully judged by the calculation of bed-days consumed. Assuming a median length of stay of 12 days (see methods), in $1989 / 90$, the 56 excess admissions per health district represented a total of 672 bed-days - the equivalent of needing an additional 25-bedded ward for 27 days, over and above existing provision.

Regarding the wider implications of our findings, although the absolute numbers of excess admissions we identified were small, the effect on bed-days was more sizeable. Against the background of increasing rates of acute hospitalization in NHS [19], the extra demand imposed by even a small number of excess admissions due to influenza may be enough to trigger a 'bed crisis'.

An alternative explanation for the small number of excess admissions we estimated is that NHS acute hospitals are so full in winter that it is not possible to admit more patients, thus imposing an artificial 'ceiling' on our estimates. The impact of influenza vaccination may also be important. Over the study period uptake in high-risk elderly persons has increased from $34 \%$ (in 1989/90) to $46 \%$ (in 1994/5) [20]. Given that influenza vaccination reduces hospital admissions in elderly persons by $63 \%$ [21], but its effect on reducing rates of infection is probably less $[22,23]$, the increases in vaccine uptake over the study period may have suppressed hospital admissions towards the end of the study but have had less impact on GP consultation rates.

Because of inadequate analysis, clinicians and health service managers may previously have overplayed the effect of influenza on excess hospital admissions. Our study demonstrates, quantitatively, that there is an excess demand for acute hospital care (due to pneumonia and influenza) among elderly persons, associated with influenza activity. To some extent this is both quantifiable and predictable allowing hospitals to draw up appropriate contingency plans.

\section{ACKNOWLEDGEMENTS}

Drs. Van-Tam and Fleming are members of Influenza Scientific Advisory Boards organised by both the Association for Influenza Monitoring and Surveillance (on behalf of the United Kingdom's influenza vaccine manufacturers) and Glaxo Wellcome Pharmaceuticals. Both of these positions attract honoraria. Dr Van-Tam was a senior lecturer at the University of Nottingham when this work was completed. However, he now works for SmithKline Beecham Pharmaceuticals but remains a visiting research fellow with the University of Nottingham.

\section{REFERENCES}

1. Farr W. Tenth annual report of the Registrar General. London: HMSO, 1847.

2. Collins SD. Influenza-pneumonia mortality in a group of about 95 cities in the United States, 1920-29. Publ Hlth Rep 1930; 45: 361-406. 
3. Serfling RE. Methods for current statistical analysis of excess pneumonia-influenza deaths. Publ Hlth Rep 1963; 78: 494-506.

4. Assad F, Cockburn WC, Sundaresan TK. Use of excess mortality from respiratory diseases in the study of influenza. Bull WHO 1973; 49: 219-33.

5. Clifford RE, Smith JWG, Tillett HE, Wherry PJ. Excess mortality associated with influenza in England and Wales. Int J Epidemiol 1977; 6: 115-28.

6. Tillett HE, Smith JWG, Clifford RE. Excess morbidity and mortality associated with influenza in England and Wales. Lancet 1980; i: 793-5.

7. Tillett HE, Smith JWG, Gooch CD. Excess deaths attributable to influenza in England and Wales: age at death and certified cause. Int J Epidemiol 1983; 12: 344-52.

8. Glezen WP, Couch RB. Interpandemic influenza in the Houston area, 1974-76. N Engl J Med 1978; 298: 587-92.

9. Barker WH, Mullooly JP. Impact of epidemic type A influenza in a defined adult population. Am J Epidemiol 1980; 112: 798-811.

10. Barker WH. Excess pneumonia and influenza associated hospitalization during influenza epidemics in the United States, 1970-78. Am J Pub Hlth 1986; 76: 761-5.

11. Fleming DM. Weekly Returns Service of the Royal College of General Practitioners. Commun Dis Publ Hlth 1999; 2: 96-100.

12. Nguyen-Van-Tam JS, Granfield R, Pearson JCG, Fleming DM, Keating N. Do influenza epidemics affect patterns of sickness absence among British hospital staff? Infect Control Hosp Epidemiol 1999; 20: 691-4.

13. Ahmed AH, Nicholson KG, Nguyen-Van-Tam JS. Reduction in mortality associated with influenza vaccine during 1989-90 epidemic. Lancet $1995 ;$ 346: 591-5.

14. Fleming DM, Zambon M, Bartelds AIM, de Jong JC. The duration and magnitude of influenza epidemics: A study of surveillance data from sentinel general practices in England, Wales and the Netherlands. Eur $\mathbf{J}$ Epidemiol 1999; 15: 467-73.

15. Curwen M. Excess winter mortality in England and Wales with special reference to the effects of temperature and influenza. In: Charlton J, Murphy M, eds. The health of adult Britain 1841-1994. Decennial Supplement No. 12. London: Office for National Statistics, 1997; 205-16.

16. Nyberg F, Pershagen G. Epidemiologic studies on ozone. Scand J Work Environ Hlth 1996; 22 (Suppl 3): 72-98.

17. Fleming DM, Cross KW. Respiratory syncytial virus or influenza? Lancet 1993; 342: 1507-10.

18. Eickhoff TC, Sherman IL, Serfling RE. Observations on excess mortality associated with epidemic influenza. JAMA 1996; 176: 776-82.

19. Harrison S. Increasing rates of acute hospitalisation: an unsystematic review of explanations. A report by the Yorkshire Collaborating Centre for Health Services Research. Leeds: Nuffield Institute for Health, 1997.

20. Irish C, Alli M, Gilham C, Joseph C, Watson J. Influenza vaccine uptake and distribution in England and Wales, July 1989-June 1997. Hlth Trends 1998; 30: $51-5$.

21. Ahmed AH, Nicholson KG, Nguyen-Van-Tam JS, Pearson JCG. Effectiveness of influenza vaccine in reducing hospital admissions during the 1989-90 epidemic. Epidemiol Infect 1997; 118: 27-33.

22. Feery BJ, Evered MG, Morrison EI. Different protection rates in various groups of volunteers given subunit influenza virus vaccine in 1976. J Infect Dis 1979; 139: 237-40.

23. Strassburg MA, Greenland S, Sorvillo FJ, Lieb LE, Habel LA. Influenza in the elderly: report of an outbreak and a review of vaccine effectiveness reports. Vaccine 1986; 4: 38-44. 